\title{
MODERN APPLICATIONS IN TECHNOLOGY OF POST AND CORE RESTORATIONS
}

\author{
MAGDALENA NATALIA DINA ${ }^{1}$, MĂDĂLINA VIOLETA PERIEANU ${ }^{2}$, RADU COSTEA $^{3}$, MIHAI \\ BURLIBAȘA ${ }^{4}$, IRINA ADRIANA BEURAN ${ }^{5}$, DANA CRISTINA BODNAR ${ }^{6}$, CAMELIA IONESCU ${ }^{7}$, \\ ŞTEFẢN MILICESCU ${ }^{8}$, NICOLETA MĂRU ${ }^{9}$, GABRIELA TĂNASE $^{10}$, ELENA-CRISTINA \\ MARCOV $^{11}$, IULIANA BABIUC ${ }^{12}$, NARCIS MARCOV ${ }^{13}$, \\ MIHAI BUTUCESCU ${ }^{14}$, LILIANA MORARU ${ }^{15}$ \\ 1,2,3,4,5,6,7,8,9,10,11,12,13,14 “'Carol Davila” University of Medicine and Pharmacy, Bucharest, \\ 15 "Titu Maiorescu" University of Medicine and Pharmacy, Bucharest
}

Keywords: post and core device, post and core reconstitution, coronary abutment, recovery
Abstract: Post and core devices are elements that contribute to the complete restoration of the coronary abutment, over which the final prosthetic restoration will be created. Their role is to retain the coronary portion of the restoration and to protect the remaining coronary structures. The retention function is dictated by the major indication of the method, massive coronary destruction that does not provide conditions for coronary aggregation of the restoration. Thus, this material is approaching two unique methods of making post and core devices totally metallic and/or hybrid (metal + totally ceramic component), using both classical technology, modern technologies, but also combinations of them.

\section{INTRODUCTION}

Restoring the integrity of the teeth has always been a necessity of humanity both for the functionality of the dentomaxillary system and for its aesthetic harmony. The reconstruction of the coronary abutment of a tooth is done with the help of post and core devices, in the conditions of an extensive dental loss, which was later followed by an endodontic treatment. $(1,2,3)$

Post and core devices are elements that contribute to the complete restoration of the coronary abutment, over which the final prosthetic restoration will be created. Their role is to retain the coronary portion of the restoration and to protect the remaining coronary structures. The retention function is dictated by the major indication of the method, massive coronary destruction that does not provide conditions for coronary aggregation of the restoration. The protection function is achieved by transmitting the occlusal forces in the root axis, along it, in the apical direction, these being distributed in the root and in the supporting marginal periodontium. Specifically, providing rigidity to the coronary device, prevents deformation of the crown edges and degradation of cement.(1-13)

Post and core devices prolong the longevity of the tooth in the dental arch, giving them a satisfactory prognosis.

\section{AIM}

Post and core reconstruction is a fixed single tooth prosthetic restoration of metal, mixed or acrylic, with the help of which the smallest usable dental portion can be restored. It has a root portion, through which it is fixed inside the root of a nonvital mono- or pluriradicular tooth, correctly root filled and a coronary portion with the help of which the crown of the tooth is partially or completely restored.

Thus, the post and core reconstructions use to the maximum the remaining dental substance, keeping at the same time their supporting periodontium, so they have a saving character of the teeth with large coronary destructions. From the point of view of the novelty of this type of single tooth prosthetic restoration, we know that they have not appeared recently, but they are not very old either.(1-13)

Specifically, the purpose of this material is to obtain an overview of the technologies for making post and core reconstructions, but focusing specifically on the technology of obtaining post and core reconstructions from metal alloys, exemplified by clinical cases presented below. More precisely, 2 unique methods of making totally metallic and / or hybrid post and core devices (metal + total ceramic component) were approached, using both classical technology, modern technologies, but also combinations of them.

\section{MATERIALS AND METHODS}

With a history of over 250 years, dental post and core have gone through several stages. In 1728, Pierre Fauchard wrote about screwing metal pivots on the root to gain support for future crowns or dental bridges. In the mid-1800s, the wooden pivot gained popularity among the dentists of the time. The great disadvantage of these pivots was that they absorbed the fluids they came in contact with, swelling and leading in time to fracture of the dental root on which they were inserted.(1-13)

Towards the end of the 19th century, metal and wooden post and core were dethroned by the Richmond crowns, which were a cast piece containing both the pivot and the dental crown, which this time was much more aesthetic, with a ceramic component. The advantages of this system were that they significantly improved the adaptation of the crown to the tooth. Nowadays, fiberglass posts are used very frequently. With a

${ }^{3}$ Corresponding author: Radu Costea, Str. Plevnei, Nr. 19, Sector 1, București, România, E-mail: mburlibasa@ gmail.com, Phone: +40723 472632 Article received on 22.07.2021 and accepted for publication on 02.09.2021 


\section{CLINICAL ASPECTS}

degree of elasticity similar to dental, made of biocompatible materials, which no longer emit oxides over time (such as metal posts), fiberglass posts have proven to be very durable over time and, in addition, they have a very high adhesion to the tooth. This material will present some very ingenious uses of post and core devices, based on a metal component.(1-13)

\section{RESULTS AND DISCUSSIONS}

\section{Clinical case no. 1}

The female patient Y.Z., aged 37, presented to the dentist's office, due to a coronary destruction following a very severe decay process, located at 3.6. Following both the oral and radiological consult, but also the patient's wishes, the dentist decided as a therapeutic solution the endodontic treatment of the affected tooth, as well as creating of a post and core device with a mixed component: metal (cobalt-chromium), and ceramic coronary part made of E.max. This hybrid solution was chosen, in order to avoid that the metal of the post and core reconstitution transparent through the walls of the future crown with a totally physiognomic coating.

Figure no. 1. Mandibular and maxillary casts positioned in occlusion

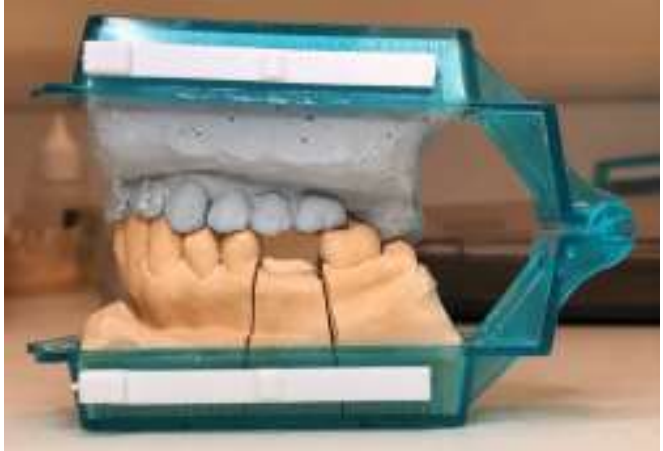

Figure no. 2. Cast post and core made of $\mathrm{Cr}$-Co alloy is reduced coronary by grinding to obtain the necessary space to create the wax framework for esthetic component

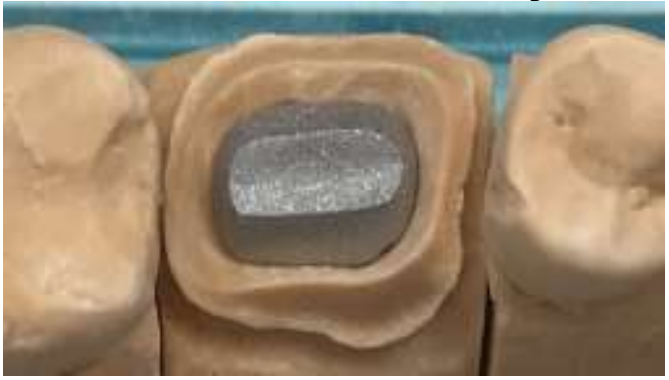

Figure no. 3. Wax framework for the esthetic component made over de metallic framework of cast post and core. It can be noticed it's accurate marginal adaptation to remaining coronal walls

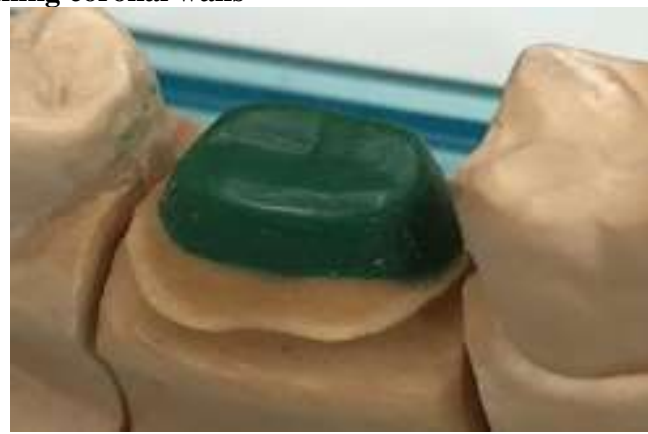

Figure no. 4. Wax framework of esthetic component attached to crucible former, ready for investing

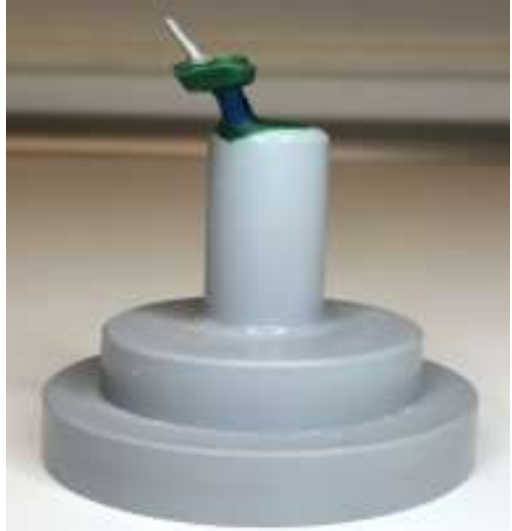

Figure no. 5. Removing the investing material by sandblasting from the surface of cast post and core

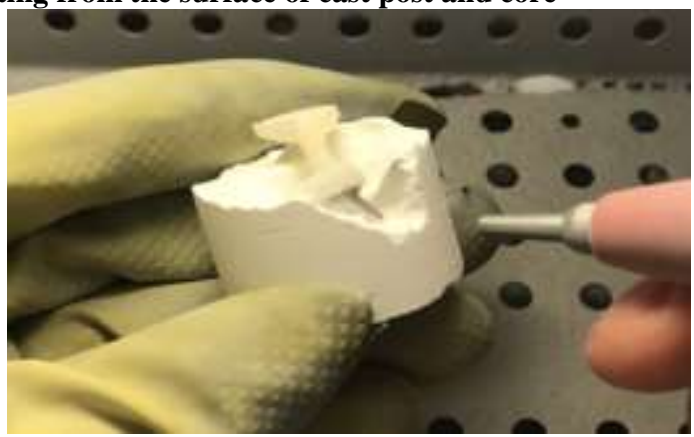

Figure no. 6. Try in on the master cast of post and core. It can notice the space between it, the neighboring teeth and antagonists kept, to ensure a minimum thickness of the crown, which will be cemented above it in the oral cavity

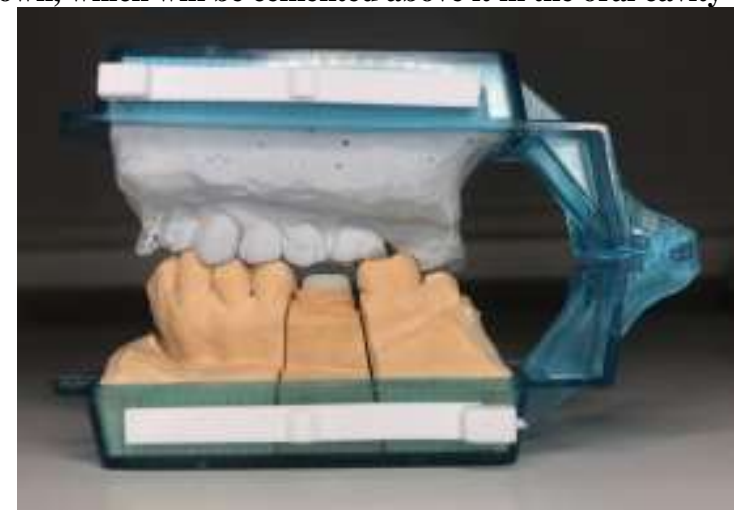

Figure no. 7. Post and core reconstitution completed

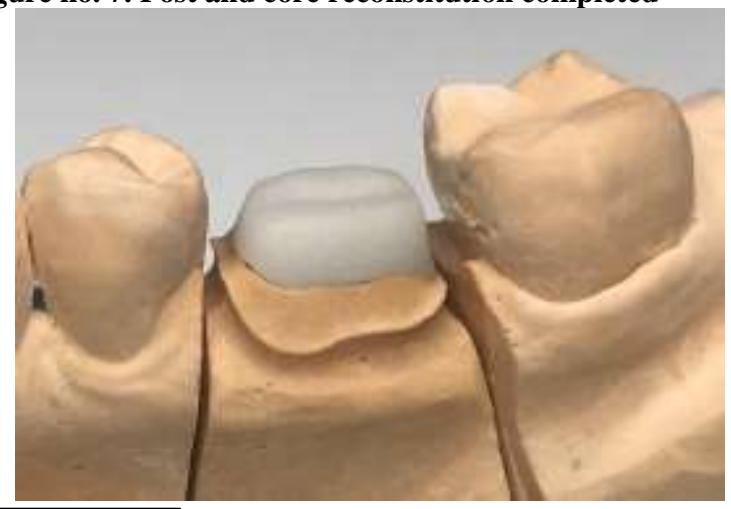

AMT, vol. 26, no. 3, 2021, p. 68 
CLINICAL ASPECTS

Clinical case no. 2

The 28-year-old V.W. patient presented to the dentist's office, due to a coronary destruction caused by a decay process, at the level of 4.4. The treatment plan established by the dentist in agreement with the patient, is to create a post and core reconstitution of chromium-cobalt alloy, to replace the lost coronal and radicular structures and to cement a totally esthetic metal-ceramic crown, to ensure proper mastication, phonation and physiognomy. The dentist asked the dental laboratory to create a post and core reconstruction by a method less common in such cases, namely by CAD-CAM method, by milling it into a disc of chromium-cobalt. The use of this state-of-the-art technology shortens the work stages and increases the accuracy of prosthetic work, and thus, the patient will benefit from a highprecision prosthetic part in a shorter time.

Figure no. 8. The maxillary working cast and the mandibular opposing cast obtained after pouring impressions of the prosthetic field

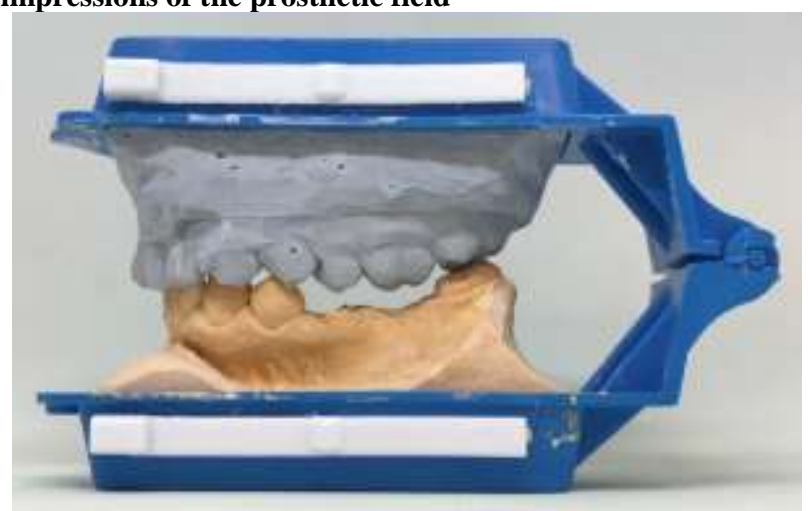

Figure no. 9. The wax framework of post and core

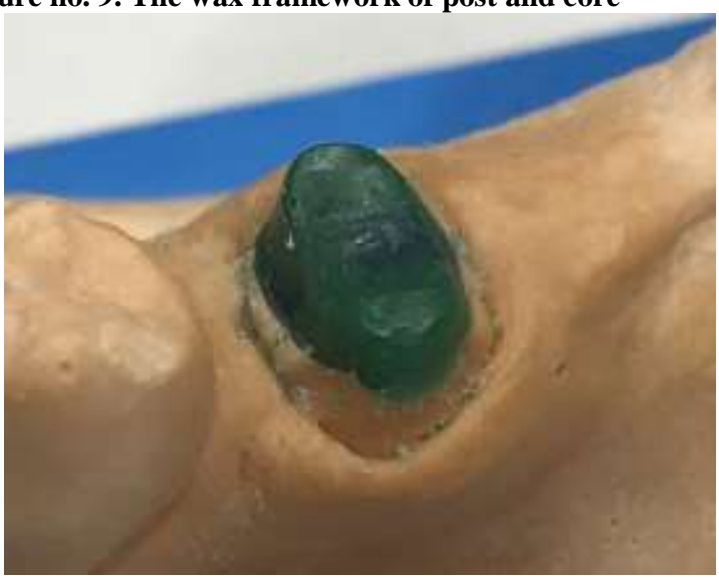

Figure no. 10. The wax framework attached with a wax rod to scanner plate

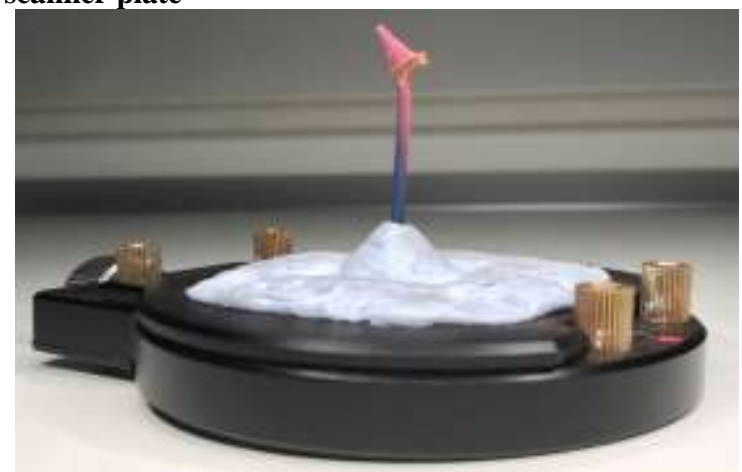

Figure no. 11. The wax framework during scanning

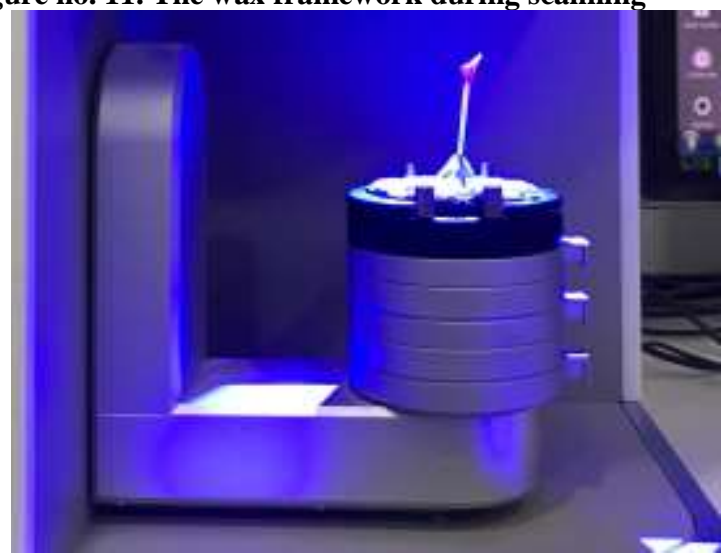

Figure no. 12. The framework scanned and visualized in collab program, the wax rod used to attach the post and core is visible in scanned image

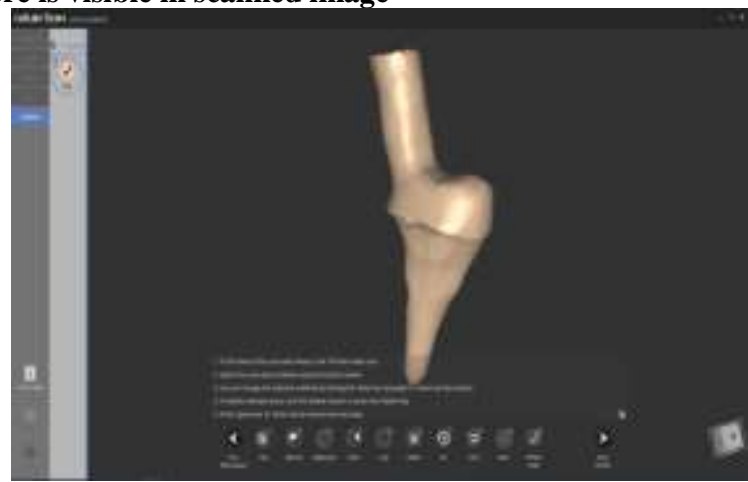

Figure no. 13. The framework imported in design program Exocad. The support rod has been eliminated

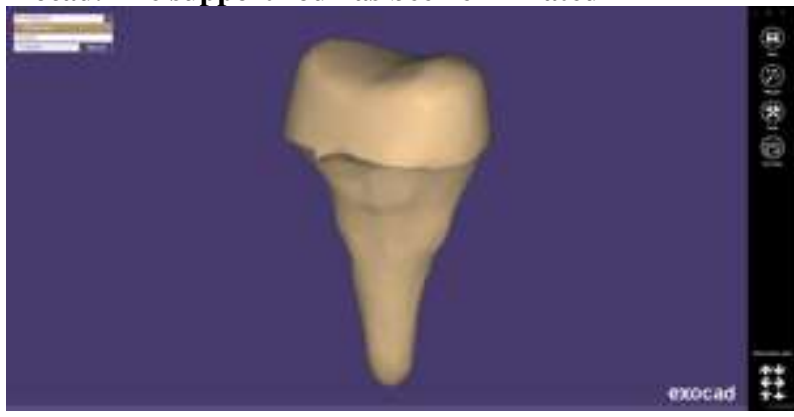

Figure no. 14. The post and core reconstruction placed on the refracting material in a metal recipient, before entering in the sintering oven

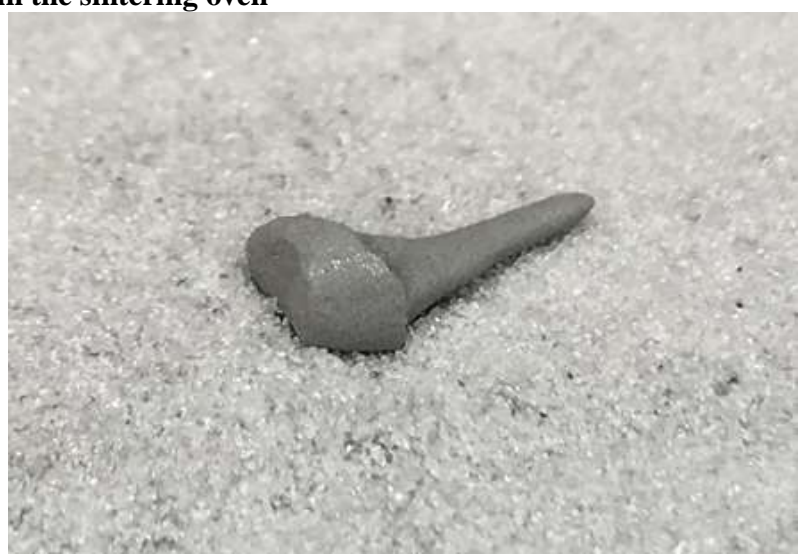

AMT, vol. 26, no. 3, 2021, p. 69 


\section{CLINICAL ASPECTS}

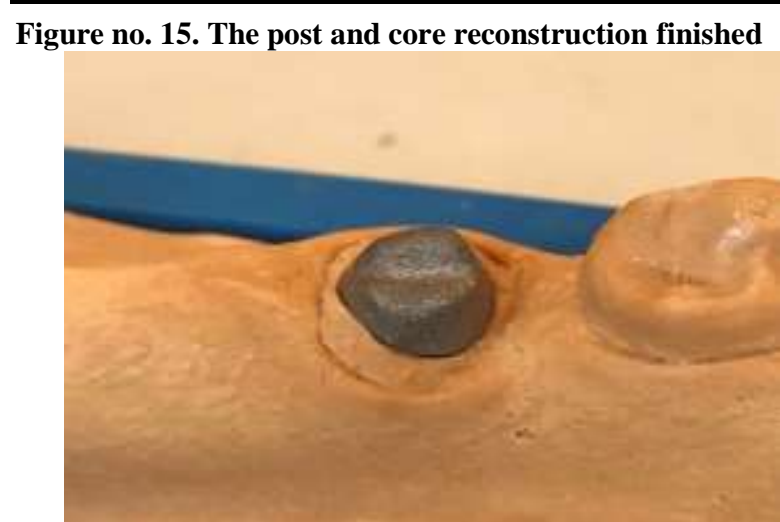

In recent decades, technology has evolved rapidly, and as a consequence, we now have high-performance equipment and technological methods. However, we must not forget the beginning, the pioneering periods, namely that the technology for making post and core reconstructions was one of choice, by casting metals.

Basically, the technology for making post and core reconstructions by casting is the safest technological method both due to its long use and the fact that the necessary materials have a much lower cost price, compared to newer generation technological processes.

Due to these aspects, the technology for creating post and core reconstructions by the method of metal casting has been practiced and is still practiced in dental laboratories in Romania, because as mentioned before, it is a cheap technique, more precisely equipment necessary are affordable, while the purchase of modern materials and equipment, as well as their maintenance requires high costs.

Of course, this technique also has disadvantages, such as: the appearance of positive and negative defects on the surface or structure of the metal, impurities from the crucible in the metal mass, a technique with a high risk of injury due to handling bodies with extremely high temperatures $\left(700-900^{\circ} \mathrm{C}\right)$ etc.

But, the technology for creating post and core reconstructions by the computerized CAD-CAM method Although it is a much more expensive method than classical technology, it is currently a much faster and safer alternative to metal alloy processing in current dental practice.

\section{CONCLUSIONS}

Even if new technologies involve a high cost of production, we must not ignore the benefits they bring. Reducing working time, increasing accuracy, reducing material waste or improving aesthetics are factors that weigh heavily in making the decision to use new technologies. And as technology becomes more accessible, it is expected that such techniques will be widely used in the future.

Acknowledgement: In this article, all the authors have equal contribution with the first author.

\section{REFERENCES}

1. Bratu D, Nussbaum R. Bazele clinice și tehnice ale protezării fixe. Editura Signata, Timişoara; 2009.

2. Pricină S, Dina MN, Perieanu MV, Burlibașa M, Ionescu I. Aspecte practice în tehnologia reconstituirii coronoradiculare. În: Tendințe moderne în științele biomedicale, Coordonatori: Burcea C.C., Neagoe I.C., Dina M.N., Perieanu V.S., Perieanu M.V. 2020;XII:148-196.

3. Vrabie AE, Ionescu C, Burlibașa M, Dina MN, Babiuc I. Modalități de refacere a bontului coronar. În: Tendințe moderne în științele biomedicale, Coordonatori: Ionescu C.,
Dina M.N., Babiuc I., Perieanu V.S., Perieanu M.V. 2020;XIV:14-47.

4. Mocuța D, Popovici IA, Burlibasa L, Cristache G, Sfeatcu $\mathrm{R}$, Bodnar T. Impact of the living conditions on population health. Metalurgia International. 2009;14:17-19.

5. Burlibasa L, Chifiriuc MC, Lungu MV, Lungulescu EM, Mitrea S, Sbarcea G, Popa M, Marutescu L, Constantin N, Bleotu C, Hermenean A. Sythesis, physico-chemical characterization, antimicrobial activity and toxicological featurs of $\mathrm{Ag}-\mathrm{ZnO}$ nanoparticles, Arabian Journal of Chemistry. 2020;13(1):4180-4197.

6. Burlibașa $M$, Cernușcă-Mițariu $M$, Cernușcă-Mițariu $S$, Mițariu M, Malița M. Theoretical and practical aspects related to biomaterials decontamination in dental medicine (with reference to dental prosthetics). Metalurgia International. 2013;XVIII(4):261-267.

7. Mocuta D, Popovici LR, Dumitriu AS, Burlibaşa L, Ionescu CA, Sfeatcu R. Life quality-condition of social welfare. Metalurgia International. 2009;14:62-64.

8. Burlibașa M, Muntianu L, Tănase G, Bucur MB, Comes CA, Ionescu CA. Study on microbial contamination of biomaterials in medical practice. Metalurgia International. 2010;XV(Spec. Issue 2):163-166.

9. Ispas DC, Eftene OA, Burlibaşa M, Bucur MB, Tănase G, Cristache CM. Implications of titanium in orthodontics and dental facial orthopedics. Metalurgia International. 2011;XVI(10):72-74.

10. Tănase G, Burlibașa M, Muntianu L, Simion I, Bucur MB, Ionescu CA. Testing the antibacterial potential of biomaterials in medical practice. Metalurgia International. 2010;XV(Spec. Issue 2):160-162.

11. Burlibașa M, Tănase G, Muntianu L, Murgu AI, Teodorescu E, Malița C. Quality of life, a multidisciplinary concept with economic and social impacts in medical practice. Metalurgia International. 2010;XV(Spec. Issue 4):88-90.

12. Burlibașa M, Cernușcă-Mițariu M, Burcea CC, Mițariu M, Ferechide D. Halogen compounds - theoretical, physiological and practical aspects regarding the decontamination, disinfection and sterilisation of instruments and biomaterials in dental medicine practice. Metalurgia International. 2012;XVIII(Spec. Issue 3):54-57.

13. Eșian D, Man A, Burlibașa L, Burlibașa M, Perieanu MV, Bică C. Salivary level of Streptococcus mutans and Lactobacillus spp. related to a high risk of caries disease. Rom Biotechnol Lett. 2017;22(2):12496-12503. 